Gerión. Revista de Historia Antigua

ISSN: 0213-0181

http://dx.doi.org/10.5209/GERI.59921

\title{
Reflexiones sobre promoción y colonización del Alto Guadalquivir en época césaro-augustea ${ }^{1}$
}

\author{
Eva María Morales Rodríguez ${ }^{2}$
}

Recibido: 21 de agosto de 2017 / Aceptado: 22 de enero de 2018

Resumen. El territorio del Alto Guadalquivir, en la provincia de Jaén, nos ha proporcionado en el estado actual de la investigación un conjunto de topónimos mayores, relacionables de forma directa e inequívoca con las ciudades romanas existentes durante la Tardía República romana y el Principado afectadas por diferentes procesos de promoción y municipalización.

Palabras clave: Hispania; municipalización; colonias; territorio giennense.

\section{[en] Reflections about the promotion and colonization of the Upper Gua- dalquivir in Caesar's and Augustus' time}

\begin{abstract}
The territory of the province of Jaén has given us the current state of research a set of toponyms older relatable directly and unequivocally with the existing Roman cities during the Late Roman Republic and the Principate affected for the different processes of promotion and the formation under municipal authority.
\end{abstract}

Keywords: Hispania; Municipalization; Coloniae; Jaén's territory.

Sumario: 1. Introducción. 2. Tardía República y Principado. 3. Estatuto jurídico y tribus. 4. Conclusiones. 5. Referencias bibliográficas.

Cómo citar: Morales Rodríguez, E. M ${ }^{\mathrm{a}}$ (2017): Reflexiones sobre promoción y colonización del Alto Guadalquivir en época césaro-augustea, en Gerión 35(2), 491-510.

\footnotetext{
1 El presente trabajo se inserta dentro de las líneas de investigación del Grupo de Investigación Arqueología e Historia en la Hispania Meridional en época romana y visigoda de la Universidad de Granada.

2 Universidad de Granada.

E-mail: evamaria@ugr.es
} 


\section{Introducción}

La tradición literaria y el material epigráfico nos han trasladado un conjunto de topónimos que sirven de referencia para el análisis del poblamiento de las tierras giennenses durante la Tardía República romana y el Principado, territorio afectado por distintos procesos de colonización y municipalización. El establecimiento de la ciudad romana fue favorecido por desarrollos históricos de naturaleza política y económica, que circunstancialmente se trazaron sobre enclaves concretos, provocando su modificación.

Tras el dilatado proceso de conquista iniciado en el s. III a.C. en el territorio del Alto Guadalquivir, con la presencia en el 211 a.C. de los Escipiones, Publio y Cneo Cornelio Escipión, que habían penetrado en el sur de la Península, base del poderío púnico, ${ }^{3}$ en su intento de frenar a Cartago ${ }^{4}$ y tomar el control de las minas de plata y plomo de la zona alta giennense, y a pesar de su trágico desenlace, analizado profusamente por Alicia $\mathrm{M}^{\mathrm{a}}$ Canto, ${ }^{5}$ el dominio de este espacio fue crucial para el avance hacia el oeste. Entre los episodios más destacables hay que citar el sitio de Iliturgi ${ }^{6}$ y la determinante batalla de Baecula en el 206 a.C., ${ }^{7}$ que conllevó el declive del dominio cartaginés. Años más tarde, hacia el 197 a.C., se emprendió la partición territorial peninsular; la parte sometida a Roma quedó dividida en dos provincias: la Citerior, al norte, y la Ulterior, al sur, con capital en Corduba.

En ese periodo de tiempo se produjeron algunas rebeliones de turdetanos, y el Senado de Roma hubo de enviar en el 195 a.C. al cónsul Marco Catón. Poco después, en torno al 179-178 a.C., aparece en escena Tiberio Sempronio Graco, que sometió diversas ciudades y aldeas. Con posterioridad se procedió a regular la situación jurídica de las distintas comunidades y oppida ibéricos de esta región, entre ellos la propia Iliturgi. ${ }^{8}$ El ulterior establecimiento de un modelo basado en la civitas, imprescindible para el organigrama de Roma, provocó profundas transformaciones que tuvieron su proyección en el ámbito jurídico y urbano (Fig. 1).

En el 143 a.C. la situación continua inestable, tal como indica Apiano, ${ }^{9}$ y algunas ciudades turdetanas de la Campiña giennense, como Tucci y Obulco, desempeñan un papel importante en los acontecimientos bélicos de la lucha de Viriato contra Roma. ${ }^{10}$ El Alto Guadalquivir tampoco fue ajeno a las disputas políticas y militares de los últimos años de la República, cuando Julio César se enfrentó a las fuerzas de Pompeyo. Se tomaron una serie de medidas con el establecimiento del modelo de civitas, célula base de la administración romana. En el ámbito jurídico algunos oppida fueron compensados con un estatuto preferente ${ }^{11} \mathrm{y}$ otros quedaron en una situación peregrina hasta la promulgación del edicto de Vespasiano, momento en que pasaron a ser municipios de derecho latino. ${ }^{12}$ Desde el punto de vista económico la política de Roma tendió tanto al control del territorio conquistado como a la explotación de los

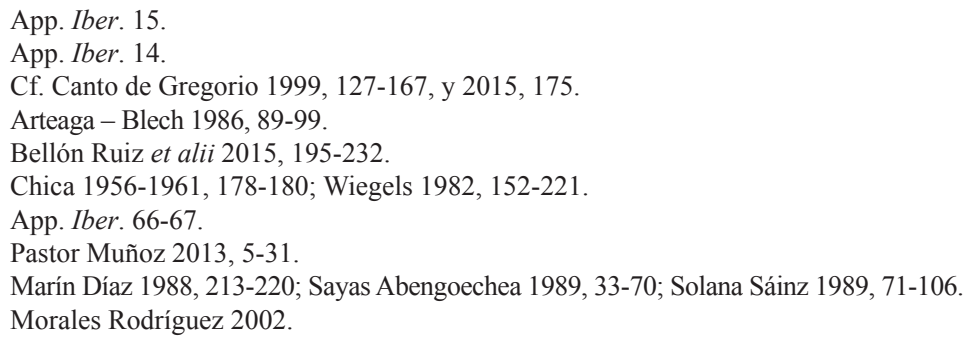


recursos naturales existentes en la zona, entre ellos, los agrarios; éstos provocaron la creación de colonias mediante el asentamiento de veteranos ${ }^{13}$ que, a través de la centuriatio y una vez dividido el territorio, recibían la correspondiente parcela. Por otro lado, los mineros favorecieron una emigración civil que se dirigió a determinados núcleos indígenas situados en las proximidades de las minas. ${ }^{14}$

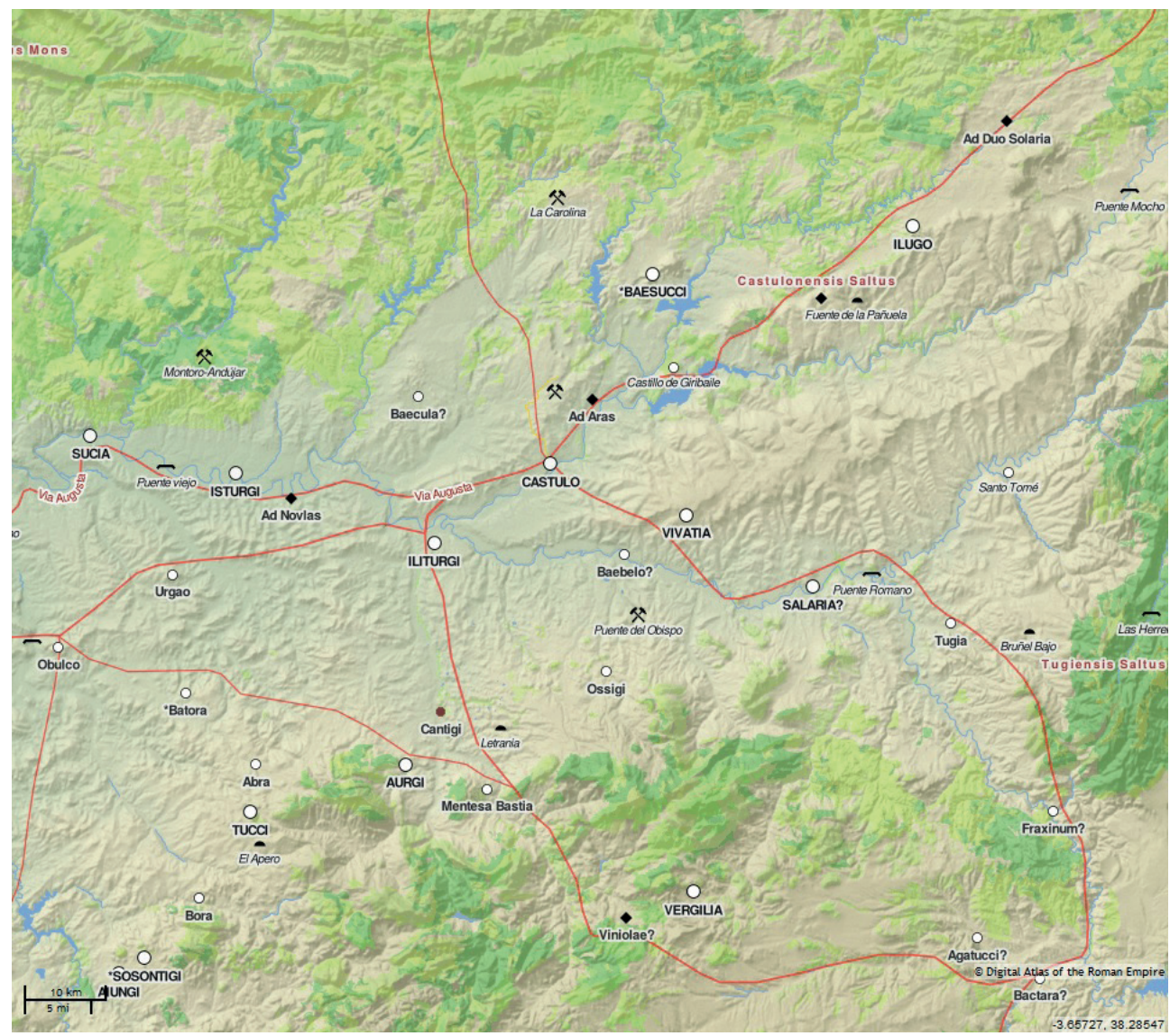

Figura 1. Ciudades romanas del Alto Guadalquivir (Geographie Datenbank Detailansicht).

\section{Tardía República y Principado}

Tras la victoria del dictador en la batalla de Munda en el 45 a.C., algunas ciudades de esta zona recibieron un estatuto jurídico privilegiado por su apoyo al bando cesariano, tal y como se pone de manifiesto en la tradición literaria antigua y en la documentación epigráfica y numismática, completada por la realidad arqueológica; se fundan colonias ex novo que controlan el territorio o se favorecen algunos de los viejos oppida con el status municipal, como es el caso de Iliturgi Forum Iulium (Cerro

\footnotetext{
13 Morales Rodríguez 2014.

14 Gabba 1973, 289-299; Marín Díaz 1988, 47.
} 
Maquiz, Mengíbar), Isturgi Triumphale (Los Villares de Andújar), Obulco Pontifciense (Porcuna), Ossigi Latonium (Cerro Alcalá, Torres) y Urgavo Alba (Arjona). Los cognomina de todos ellos muestran una afinidad evidente con la historia de la familia cesariana, y permiten considerar la posibilidad de que la promoción al rango municipal pudiese producirse con César o, a lo sumo, con anterioridad al 27 a.C. ${ }^{15} \mathrm{El}$ carácter municipal queda reiteradamente documentado en los distintos epígrafes. ${ }^{16}$

El proceso de control de este espacio abre paso a un periodo decisivo de dominio durante la Tardía República y Principado, en el que se dibuja un innovador plano de comunidades privilegiadas. La obra del dictador, o la extensión de la ciudadanía proyectada por éste, es continuada por su heredero Augusto, aunque con tintes distintos, lo que se vincula al carácter militar de las colonias y a la compensación de los veteranos de guerra. A este momento corresponde la deductio de dos importantes colonias en las comarcas de la Loma y la Campiña giennense, Salaria (Úbeda la Vieja) y Tucci (Martos). Los factores de índole estratégica fueron claves en este desarrollo. La división de la provincia Hispania Ulterior en dos sectores, que elevó a tres el total de provincias, tal y como señala Dión Casio, ${ }^{17}$ afectó a esta área del sur peninsular. El limes no fue el mismo, se amplían los territorios de la Tarraconensis a expensas de la Baetica y la Lusitania. ${ }^{18}$ Entre el 7 y 2 a.C. Augusto decide integrar los distritos mineros de Castulo (Linares) y Acci (Guadix), así como la franja al este y norte de la actual provincia de Almería, en la Tarraconensis, bajo su control directo. ${ }^{19}$ Estas alteraciones supusieron incluir ciudades como Castulo, Baesucci, Salaria, Vivatia, Tugia, etc. En consecuencia, tras esta definitiva división del reinado augusteo, las tierras del Alto Guadalquivir quedaron fragmentadas administrativamente entre dos provincias: buena parte de su mitad occidental quedó adscrita a la Baetica, y el resto del territorio a la Tarraconensis; y con ello, las colonias de Tucci, al sur, y Salaria, al norte, van a constituirse como los ejes principales de este ordenamiento territorial (Fig. 2). Plinio ${ }^{20}$ nos señala que el Betis nace en las proximidades del saltus Tugiensis y, tras atravesar Ossigitania, se adentra en la Bética, donde existen numerosas poblaciones: al conventus Cordubensis adscribe, a la orilla misma del río, Ossigi Latonium, Iliturgi Forum Iulium, Isturgi Triumphale, Ucia y Obulco Pontificense; ${ }^{21}$ al conventus Astigitanus asigna la colonia inmune Tucci Augusta Gemella. Por su parte la colonia Salariense y Castulo, que considera población de derecho latino viejo, ${ }^{22}$ quedan al otro lado de esta linde. A partir de los datos aportados por Plinio podemos seguir como frontera una línea que, de norte a sur, se sitúa desde Sierra Morena, entre el Jándula y el Rumblar, parte del Guadalquivir, con Castulo al este, en la Tarraconensis; continúa por el curso del Guadalbullón y Sierra Mágina por el sur. Esta nueva línea divisoria sigue el camino por el que el mineral de los valiosos yacimientos de la región minera de Castulo era transportado a la costa almeriense para su fletamento.

\footnotetext{
Marín Díaz 1988, 219.

Iliturgi: CILA 6, 225; Isturgi: CILA 6, 265, 266; Obulco: CILA 6, 297, 299, 303, 306; Urgavo: CILA 7, 558, 564, 565. 


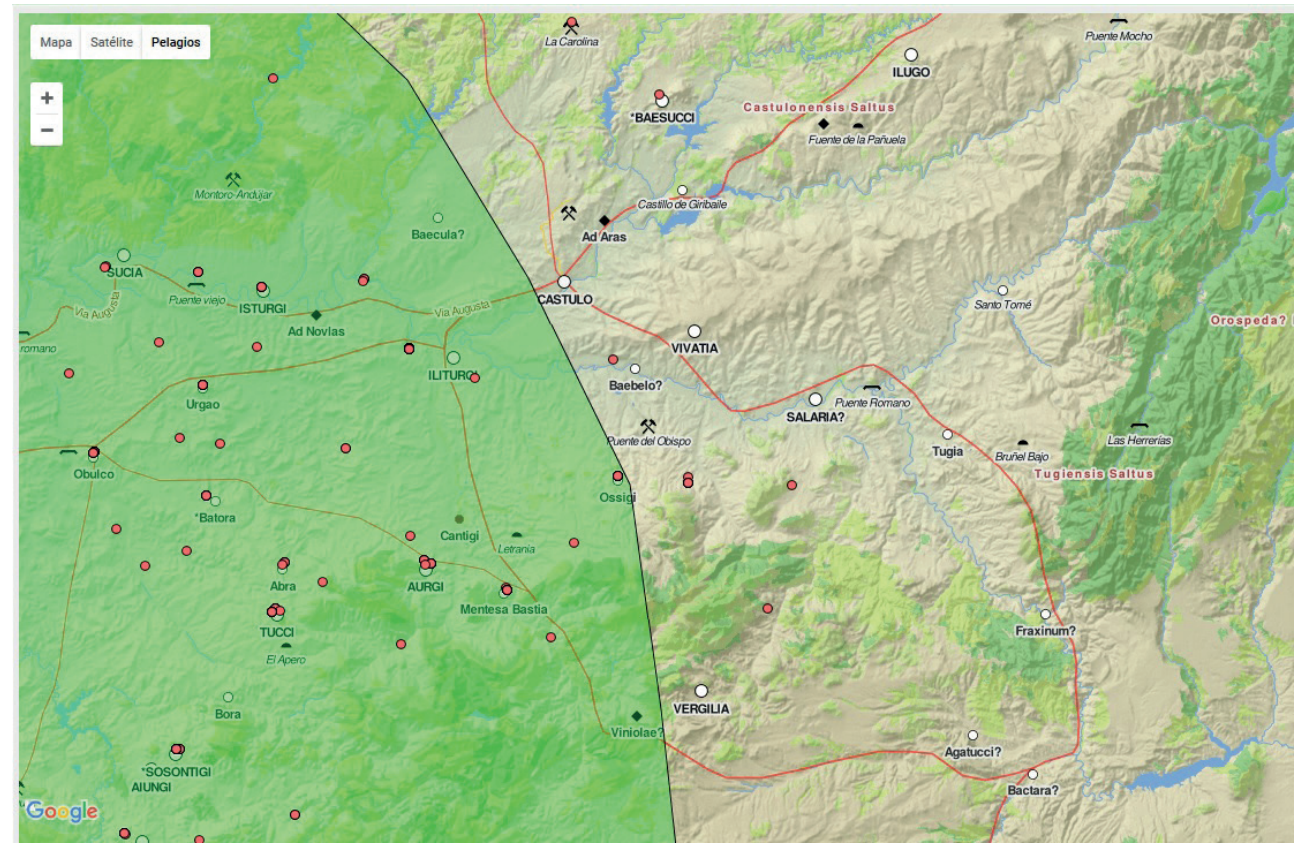

Figura 2. Limes Baetica-Tarraconensis en el Alto Guadalquivir (Geographie Datenbank Detailansicht).

El geógrafo Estrabón ${ }^{23}$ también muestra la situación de estas comunidades en la ruta militar más importante que cruzaba la Hispania meridional, la Vía Augus$t a$, que tiene como curso de enlace el Guadalquivir. Procedente de Corduba tiene parada en Castulo en dirección Carthago Nova; trazado que queda registrado en el Itinerarium Antonini Augusti con el trayecto Item ab Arelato Narbone, inde Tarracone, Karthagine Spartaria, Castulone, con 732 m.p., y otro en dirección sur Item a Castulone Malacam, con 276 m.p. Otro ramal recogido en los vasos de Vicarello continúa hacia Saetabis. Este carácter de cruce de caminos permitió el protagonismo comercial de Iliturgi Forum Iulium o Isturgi Triumphale, municipios situados en el contacto de la depresión Guadalquivir-Guadalbullón, como el centro minero de Castulo, u otras aglomeraciones situadas en la ruta del Guadalimar con las tierras de Albacete, o en la del Guadalbullón, como Mentesa, a través de las sierras béticas con el área de Guadahortuna, con el este a través de la colonia Iulia Gemella Acci, Basti y Carthago Nova o hacia el sur con Malaca. De este último tramo nos interesa especialmente un recorrido que pasaría por el enclave de Mentesa Bastia, ya que de esta localidad procede una columna miliar catalogada como CILA 7, $625,{ }^{24}$ conservada en el Museo Provincial de Jaén, y que ofrece una cronología del año 8-7 a.C., fecha de la XVI tribunicia potestad de Augusto, quien mandó construir esta calzada. La ruta es resultado de la actividad augustea en estas tierras meridionales, en un contexto de promociones, fundaciones y concesiones de privilegios. Posteriormente, se han

\footnotetext{
Str. 3.4.9.

${ }^{24}$ CIL II 4931 (=CILA 7, 625): Imp(erator) $\cdot$ Caesar $\cdot$ Augustus / Divi $\cdot f($ ilius $) \cdot c o(n) s(u l) \cdot X I /$ tribunicia $\cdot$ potestate $\cdot X V I / I m p($ erator $) \cdot X I I I \cdot$ pontufex $\cdot \max ($ imus $)$.
} 
encontrado seis miliarios procedentes de La Cerradura datados en el reinado de Adriano y la Tardía Antigüedad, fruto de las reparaciones posteriores. ${ }^{25}$ A partir de estas dataciones podemos señalar dos momentos constructivos, cronológicamente sucesivos: el primero fechable en época augustea, tendría como propósito enlazar los núcleos del interior y Malaca con su puerto, uno de los más importantes de la época; el segundo momento estaría íntimamente ligado a las transformaciones llevadas a cabo por los emperadores posteriores con el mantenimiento de una vía esencial del sur peninsular, que se amortiza, con una clara finalidad de abastecimiento y control territorial.

\section{Estatuto jurídico y tribus}

Otro aspecto de estas ciudades peregrinas promocionadas, como se testimonia en Plinio, ${ }^{26}$ es la adscripción de sus ciudadanos a la tribu Galeria. ${ }^{27}$ Así Obulco, referenciada en la tradición literaria y en la documentación epigráfica, ratifica su localización con la actual Porcuna. Su secuencia ocupacional se extiende desde el Calcolítico hasta el reinado de Tiberio y Claudio, ${ }^{28}$ con continuidad a lo largo del periodo altoimperial. Sus ciudadanos se adscribieron a la tribu Galeria $^{29}$ y logró alcanzar la categoría de municipium en época de César o en el reinado de Augusto. Entre los descubrimientos arqueológicos destaca un conjunto de construcciones junto a un espacio enlosado, que Oswaldo Arteaga data en la segunda mitad del siglo I a.C. ${ }^{30} \mathrm{~A}$ partir de la etapa flavia se produce un abandono de ciertos sectores urbanos, aunque no un decaimiento total. ${ }^{31}$ En esta línea se pueden interpretar los vestigios descubiertos en la barriada del Hoyo Mendo, dados a conocer por la Sociedad Arqueológica Arqvipo. Se trata de varios metros de muros en sillería almohadillada, pertenecientes a un edificio -interpretado como el anfiteatro del municipio- fechable en los años centrales del siglo I d.C. ${ }^{32}$

En la misma perspectiva Isturgi, situada en la comarca de la Campiña y junto al Betis, aparece entre las poblaciones del Conventus Cordubensis. Contamos con referencias a su nueva situación jurídica como municipium ${ }^{33}$ o como res publica, ${ }^{34}$ así como a la tribu Galeria, ${ }^{35}$ como indicio de su promoción. Las referencias al urbanismo de la ciudad están presentes en la obra de Juan Agustín Ceán Bermúdez, que alude a la existencia de estructuras constituidas por una muralla, un acueducto, una

25 Sillières $1976,55-70$.

26 Plin. HN 3.3.10.

27 Iliturgi: CILA 6, 233; Isturgi: CIL II 2121 (=CILA 6, 265); Obulco: CIL II 2126 (=CILA 6, 297), CIL II 2129 (=CILA 6, 299), CIL II 2130 (=CILA 6, 300), CIL II 2131 (=CILA 6, 302), CIL II 2132 (=CILA 6, 303), CIL II 2134 (=CILA 6, 305) y CIL II 2149 (=CILA 6, 329); Urgavo: CIL II 2105 (=CILA 7, 558), CIL II 2114 (=CILA 7, 567), CIL II 2115 (=CILA 7, 568) y CIL II 2118 (=CILA 7, 573).

28 Morales Rodríguez 2013, 93, y 2015, 89-101; Fornell Muñoz 2015, 23.

29 Wiegels 1985, 50, en CIL II 2131 (=CILA 6, 302), CIL II 2126 (=CILA 6, 297), CIL II 2130 (=CILA 6, 300), CIL II 2129 (=CILA 6, 299), CIL II 2132 (=CILA 6, 303), CIL II 2149a (=CILA 6, 329), CIL II 2134 (=CILA 6, 305), CIL II 2144 (=CILA 6, 317), y Kubitschek 1972, 179.

$30 \quad$ Arteaga $1985,286$.

31 Arteaga - Ramos - Roos 1990,315-316.

32 Arqvipo 2015: http://www.europapress.es/andalucia/fundacion-cajasol-00621/noticia-jaen-cultura-investigadoresporcuna-descubren-anfiteatro-romano-antigua-obulco-20150212120439.html.

33 CIL II 2121 (=CILA 6, 265) y CIL II 2122 (=CILA 6, 266).

34 CIL II 2124 (=CILA 6, 269).

35 CIL II 2121 (=CILA 6, 265). 
cisterna y diversas edificaciones. ${ }^{36}$ Lo que se ha analizado en profusión es el gran barrio artesanal documentado en las diversas campañas arqueológicas dirigidas por los profesores Manuel Sotomayor, Mercedes Roca y $\mathrm{M}^{\mathrm{a}}$ Isabel Fernández, barrio que acogió el alfar más importante en la producción de terra sigillata hispánica de la Hispania meridional. ${ }^{37}$

De igual modo, contamos con otros datos que señalan la integración de ciertos oppida en el marco de relaciones con Roma. Al este de Obulco se ha identificado uno de ellos; nos referimos a Batora, identificada en Torre Benzalá, donde existen vestigios arqueológicos de época romana. ${ }^{38}$ En este enclave, del que desconocemos su situación jurídica anterior, se documenta la presencia del ordo Batorensis, del duovirato y del pontificado en la figura de P. Fabius P. f. Gal. Iulianus, IIvir bis, pontifex. La madre de este magistrado, Iunia M. $f$. Severa, pagó la inscripción y sufragó los honores decretados por el ordo a su hijo, un pedestal datado en el periodo augusteo y vinculado a este enclave de status privilegiado. ${ }^{39}$ Otro indicio de promoción se presenta en las proximidades de Santo Tomé, donde tenemos la referencia de un miembro de la gens Fulvia también adscrito a la Galeria tribus ${ }^{40}$ lo que nos permite apostar por un posible status privilegiado que no podemos detallar.

Por otro lado, el exiguo material epigráfico delata la latinización de la onomástica en individuos originarios de las antiguas oligarquías ibéricas (nomen latino + cognomen ibérico) y el desempeño de las magistraturas en las nuevas comunidades, como ocurre en los casos de Urgavo Alba o Castulo. De Arjonilla procede un interesante friso funerario atribuido a la tumba de M. Horatius M. $f$. Gal. Bodonilur, IIvir, y su cónyuge Lucretia L. f. Sergieton (vid. infra, Fig. 8), ${ }^{41}$ donde aparecen dos escenas agrarias que representan dos personajes portando arados y unos bueyes roturando la tierra, relieve que podría estar en relación con la promoción de la ciudad; concretamente, el acto religioso que convalida la fundación del nuevo municipio en época de Augusto. Podemos llegar a pensar que este individuo fuese partícipe de esta conmemoración y lo deja reflejado en su monumentum post mortem. En la misma línea de aculturación del sistema onomástico indígena se encuentra el epígrafe de C. Cornelius Brocchus, procedente del Caserío de la Huelga, en Linares. ${ }^{42}$

Por otra parte, se ponen en marcha otra serie de medidas como la colonización del territorio mediante población de origen latino, en su mayor parte ciudadanos adscritos a la tribu Sergia. Aunque escasa, se constata la presencia foránea de gentes itálicas, como los Stlaccii en un monumento de Salaria. La colonia Salaria estuvo incluida en el territorio de la provincia romana de la Bética hasta el 14 a.C.; posteriormente, tras las reformas administrativas de Augusto, pasó al Conventus Carthaginiensis y, en consecuencia, a la Provincia Hispania Citerior Tarraconense. En su ordenamiento territorial, su posición era excéntrica; de hecho, su ager se ubicaba en el confín de

\footnotetext{
Ceán Bermúdez 1832, 381.

37 Fernández - Ruiz - Peinado 2008, 173-188.

38 Recio 1969, 31-37, n 46.

39 CIL II 1677 (=CILA 6, 70=CIL II $\left.{ }^{2} / 5,60\right)$ : P(ublio) Fabio P(ubli)f(ilio) / Gal(eria) Iuliano / IIvir(o) bis pont(ifici) / ordo Bator(ensi)s / decrevit / Iun(ia) M(arci) f(ilia) Severa / mater / honore usa / impens(am) remissit(!)) y CILA 6, 71: ordo Batorensis.

40 CILA 7, 370.

${ }^{41}$ CIL II $2114(=$ CILA 7, 567): M(arcus) $\cdot$ Horatius $\cdot M($ arci) $\cdot f($ ilius $) \cdot /$ Gal(eria $) \cdot$ Bodonilur $/$ II $\cdot$ vir $\cdot$ Lucretia $\cdot$ L(ucii) $\cdot$ f(ilia) $\cdot /$ Sergieton $\cdot$ uxor.

42 CIL II 3293 (=CILA 6, 127): C(aius) · Cornelius / C(ai) · f(ilius) · Gal(eria) / Brocchus / - - - - - - .
} 
la provincia y colindaba con el territorio bético, del que le separaba el río Betis y Sierra Mágina.

Como ocurre en la mayoría de las ciudades hispanas, la tradición literaria transmitida menciona a Salaria tan sólo de forma puntual; la primera referencia conservada tiene un contenido eminentemente administrativo y procede de la Naturalis Historia de Plinio ${ }^{43}$ cuyas fuentes de información remiten en este caso a inicios del principado; concretamente, se la cataloga entre los 65 populi adscritos al Conventus Carthaginiensis, y se refiere su estatuto colonial. En cambio, la alusión de Ptolomeo posee un carácter étnico-geográfico, ya que incluye a Salaria entre las polis de los oretanos, cifrando sus coordenadas en $9^{\circ} 20^{\prime} 40^{\prime \prime}, 4^{4}$ mientras que en otro pasaje, la sitúa en las coordenadas $13^{\circ} 39^{\prime} 40^{\prime \prime}$, y la cataloga como polis bastetana, sin duda un error. ${ }^{45}$ Situada muy cerca del centro oretano de Castulo, se ubicaba en una situación geopolítica fundamental en las comunicaciones entre el este de la Península Ibérica y el alto valle del Guadalquivir. Este territorio fue desde época muy temprana un foco de atracción de itálicos dedicados a los negocios de la minería y a las actividades comerciales.

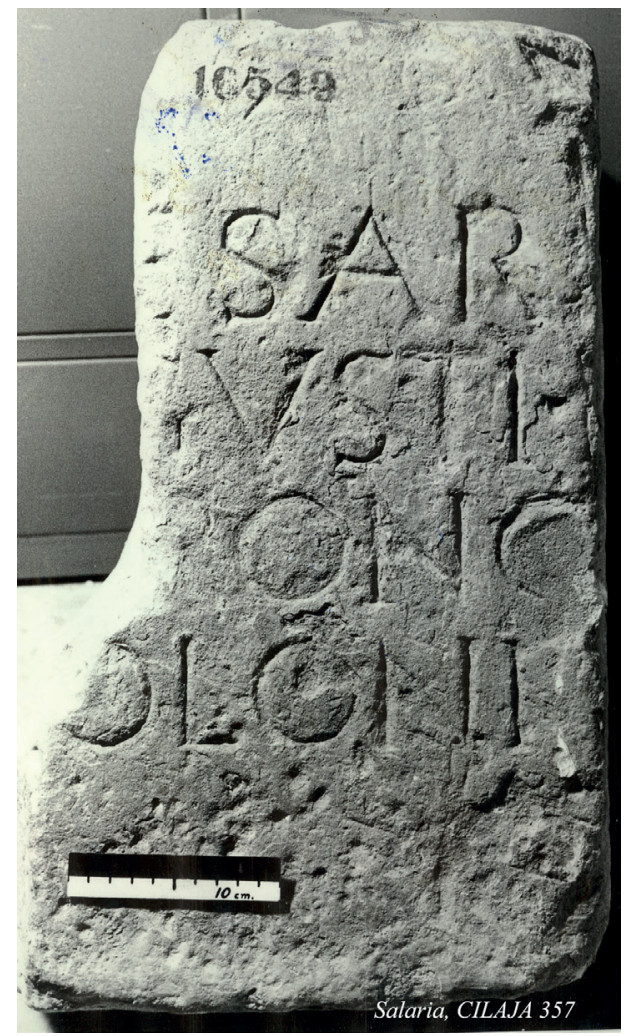

Figura 3. CILA 7, 357: Inscripción honorífica dedicada al hijo adoptivo de Augusto por parte de los colonos de Salaria.

\footnotetext{
Plin. HN 3.4.25.

44 Ptol. 2.6.58.

45 Ptol. 2.6.60.
} 
Por lo tanto, se identifica con las ruinas de "Úbeda la Vieja", a unos $15 \mathrm{~km}$ al sureste de Úbeda, en las estribaciones de la comarca de La Loma, en las proximidades de la desembocadura del río Jandulilla en el Guadalquivir, en el paraje del Cortijo de $\mathrm{D}^{\mathrm{a}}$ Aldonza; de hecho, el epígrafe CILA 7, $357^{46} \mathrm{y}$ el publicado por $\mathrm{H}$. Gimeno, ${ }^{47}$ claramente constatan su status de colonia, mientras que CILA 7, 364 ${ }^{48}$ (Fig. 3) muestra el topónimo como origo.

Sobre el núcleo indígena prerromano, con una secuencia ocupacional que remite al Bronce Pleno, ${ }^{49}$ se procede a realizar la deductio de la colonia romana de Salaria, cuya fecha exacta de fundación es difícil señalar, debido a la escasez de datos; no obstante, tal fecha se puede establecer entre el 45 a.C., tras la batalla de Munda-con las concesiones de ciudadanía llevadas a cabo por César en el sur peninsular- y el 14 a.C., con motivo de la tercera estancia de Augusto en Hispania y cuando procede a asentar veteranos en áreas estratégicas y a llevar a cabo una serie de reformas en el ordenamiento territorial mediante la creación de la provincia de la Baetica, entre el 25 y 12 a.C., y la construcción de la Vía Augusta.

Podemos debatir si se trata de una fundación de César o Augusto a partir de las tribus, como analizaremos más adelante; pero los veteranos militares, que pudieron proceder a su deductio colonial, no se han constatado. No disponemos de datos que precisen su componente social. De igual modo, la carencia de cognomina en su titulación dificulta conocer la época de su creación. José $\mathrm{M}^{\mathrm{a}}$ Solana señala que la ausencia de cognomen no implica que se trate de una fundación republicana. ${ }^{50}$

Un elemento de referencia en el debate sobre el momento fundacional está constituido por las tribus a las que se vinculan los colonos. Sus ciudadanos se adscribieron administrativamente a dos tribus, la Sergia ${ }^{51}$ y la Galeria ${ }^{52}$ la presencia de la primera es incuestionable, pues se documenta en una inscripción procedente de Toya; concretamente, esta inscripción se encontraba empotrada en la torre árabe cuando fue descrita por Martín Jimena Jurado en 1639, posteriormente fue extraída por Tomás Román Pulido a principios del s. XX y llevada al Museo Arqueológico Nacional (Fig. 4). En la misma, datada en el s. I d.C., dos magistrados religiosos, un flamen y una flaminica de la Provincia Hispania Citerior (L. Po[stu]mius Q.f. Serg. Fabul[lus flamen] Augus[tor]um provinc(iae) His[paniae Cit(erioris), tribunus militum] legionis VII, [IIv] ir colonia[e Salariae] y Manlia [L.] f. Silana), hacen una dedicación. ${ }^{53}$

${ }_{46}$ CIL II 5093 (=CILA 7, 357): [C(aio)? Ca]esari [· Divi / Au]gusti $\cdot f($ ilio) $[\cdot$ pa]/trono / [c]oloni.

47 Gimeno Pascual 2004-2005, 181-184 (=HEp 14, 2005, 192): D(is) $\cdot$ M(anibus) $\cdot s($ acrum) / M(arcus) $\cdot$ Iulius M(arci) $\cdot f($ ilius) / Galeria Aemilia/nus col(onia) Salar(ia) / IIvir bis fla/men Romae et Aug(ust-) / annor(um) $X X X X V /$ [pi]us in suis $\cdot h$ (ic) s(itus) est /s(it) t(ibi) ter(ra) levis / [A]elia Secundina / uxor · posuit.

${ }_{48}$ CILA 7, 364: D(is) $\cdot$ M(anibus) $\cdot s$ (acrum) $\cdot /$ Laelia $\cdot$ Rhodope / C(ai) $\cdot$ Laeli $\cdot$ Sedati $\cdot$ lib (erta) / Salariensis / [annor(um)] $\cdot$ L $\cdot$ pia $\cdot$ in $\cdot$ suis $\cdot$ hic $\cdot$ sita $\cdot$ est.

49 Excavaciones de Molina et alii 1978, 37-58.

50 Solana $1989,85$.

51 Wiegels 1985, 133, en CIL II 3329, y Kubitschek 1972, 198-199.

52 Cf. Gimeno Pascual 2004-2005, 181-184.

53 CILA 7, 542: L(ucius) $\cdot$ Po[stu]mius $\cdot Q($ uinti) $\cdot f($ ilius $) \cdot \operatorname{Serg}($ ia $) \cdot$ Fabul[lus? flamen] / Augus[tor]um provinci(ae) $\cdot$ His [paniae $\cdot \operatorname{cit}($ erioris $) \cdot$ trib(unus) $\cdot$ mil(itum)] / leg(ionis) $\cdot$ VII $\cdot[$ IIV] ir colonia [e $\cdot$ Salariae $\cdot$ et] /Manlia $\cdot[L($ uci $) \cdot] f($ ilia $) \cdot$ Silana $\cdot$ fla[minica] / eiusdem $\cdot$ provinc (iae) $\cdot[$ dederunt $) \cdot d($ edicaverunt $)](=C I L$ II 3329=ILER 1658); Wiegels 1982, 133, no 320; Alföldy 1973, 86, nº 58; PME P 103; Curchin 1990, $223, \mathrm{n}^{\circ} 881$. 


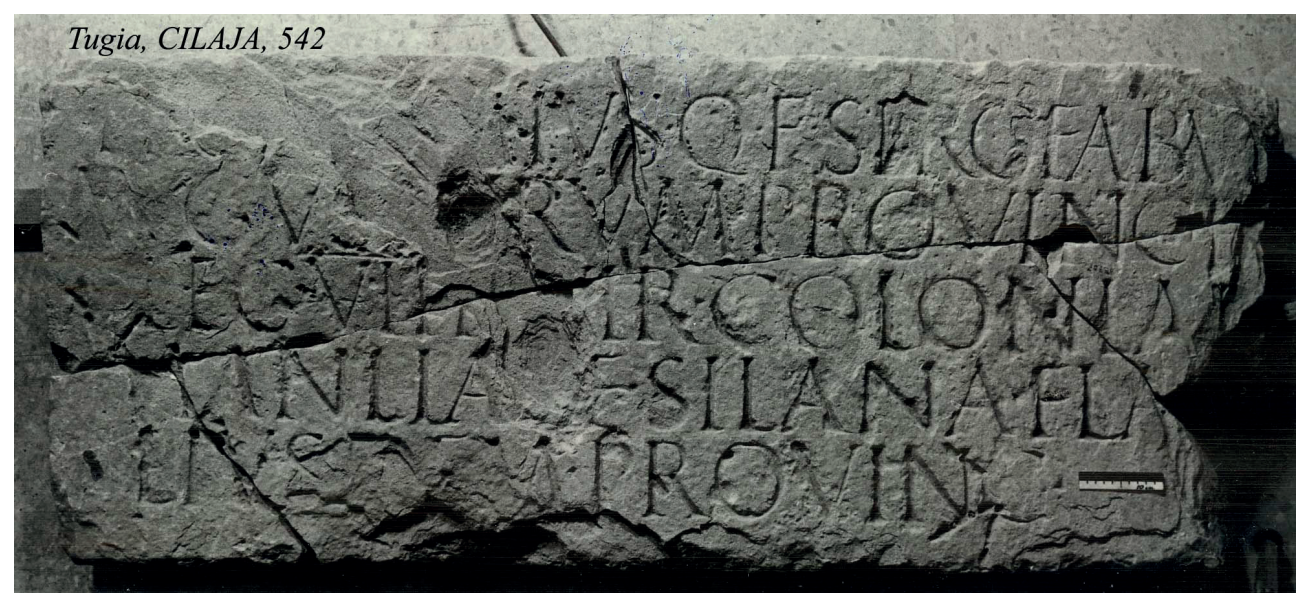

Figura 4. CILA 7, 542: Inscripción salariense con mención de la tribu Sergia.

Otro epitafio salariense relacionado con esta tribu (CILA 7, 365; Fig. 5) ha suscitado debate en cuanto a su lectura y datación; el desacuerdo reside en el desarrollo de la segunda línea: Cristóbal González y Julio Mangas - que fechan el epígrafe en época julio-claudia- leen $\mathrm{Se}[x($ tus $)] ;{ }^{54}$ mientras que un segundo planteamiento, liderado por Armin U. Stylow ${ }^{55}$ y seguido por Luis Baena y José Beltrán, ${ }^{56}$ propone Se [rgia]. La discrepancia en este segundo planteamiento radica en la datación; mientras que Stylow presenta una cronología para la segunda mitad del s. I a.C., Baena y Beltrán señalan una datación que iría desde el reinado de Augusto hasta mediados del siglo I d.C. Por tanto, si admitimos que estos ciudadanos se adscriben a la tribu Sergia, podríamos tener otro indicio cronológico relacionado con los primeros momentos de andadura de la colonia.

La importancia de la difusión de la tribu Sergia en el territorio de la provincia Tarraconense ha sido analizada por Donato Fasolini ${ }^{57}$ y se constata en otras ciudades de estatuto privilegiado como Carthago Nova, Consabura, Emporiae, Libisosa y Tarraco. Su cronología ha suscitado distintas opiniones: Joseph Wilhelm Kubitschek ${ }^{58}$ y Carmen Castillo, ${ }^{59}$ la relacionan con las concesiones de ciudadanía de César; Robert C. Knapp, en el caso de Corduba, prefiere su vinculación con ciudades latinas antes del 45 a.C. ${ }^{60}$ mientras que Julián González, tomando como prototipo la colonia de Urso, defiende la concordancia tribu Sergia con enclaves privilegiados de fundación republicana, incluyendo las creaciones previas a Augusto. ${ }^{61}$

CILA 7, 365: M(arcus) - Stl[accius $\cdot$ et] / Se[xtus] / Stlacc[ius] / sibi $\cdot$ et $\cdot$ s[uis $\cdot$ f(ecerunt)].

Stylow 1993, 85, n. 57: M(arcus) $\cdot \operatorname{Stl}[$ accius $\cdot f \cdot] / S e[r g(i a)] / S t l a c c[i a] /$ sibi $\cdot$ et $\cdot[$ viro? $\cdot f ?$ )].

Baena - Beltrán 2002, 145 y ss. (=HEp 6, 1996, 624).

Fasolini 2012.

Kubitschek 1972, 198-199.

Castillo 1988.

Knapp 1980, 61-71.

González 1989, 133-153. 


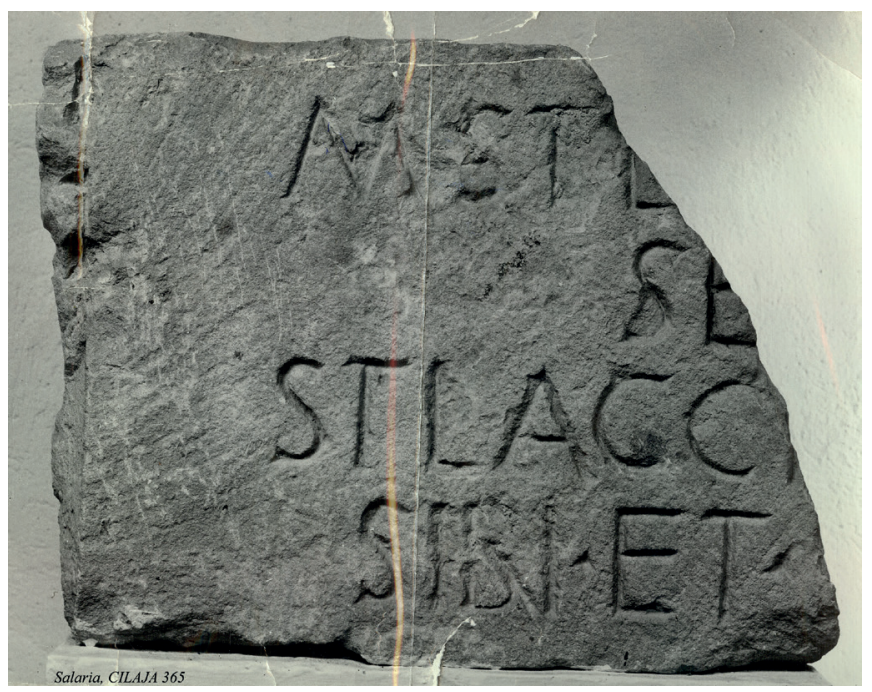

Figura 5. CILA 7, 365: Inscripción salariense relativa a un inmigrante itálico.

Salaria pudo recibir un contingente de veteranos después de la batalla de Munda o bien pudo integrar a elementos civiles procedentes de Italia, que venían a establecerse a Hispania, contribuyendo a su fundación. Podría admitirse una fundación colonial mixta. Este contingente se sumaría al elemento autóctono, confirmado por los materiales cerámicos de época ibérica.

En segundo lugar, se testimonia la tribu Galeria, así en un pedestal que se fecha en el s. II d.C., ${ }^{62}$ donde aparece M. Iulius Aemilianus, que desempeñó dos veces el duovirato en la colonia y también ejerció el flaminado. ${ }^{63} \mathrm{Al}$ programa augusteo se atribuye la adscripción de los ciudadanos a la Galeria en colonias como Tarraco, Barcino, Itucci, Libisosa, Ucubi o Pax Iulia, además de determinadas tribus "insólitas" en el panorama hispano, como la Aniensis de Caesaraugusta, la Papiria de Augusta Emerita y Astigi, o la Pupinia de Acci.

La singularidad de la doble adscripción no es un caso aislado en la Hispania meridional. No sabemos, a falta de epítetos en el caso de la colonia Salaria, si su doble tribu pudo haber correspondido o no a un dúplice asentamiento, como se ha propuesto en el caso de otras colonias como Corduba, Tucci, Urso o Hispalis, ${ }^{64}$ ambas pudieron coexistir desde su fundación. En opinión de J. González la existencia de ambas tribus implicaría dos etapas en el proceso de concesión de la ciudadanía romana a dos colectivos diferentes, veteranos cesarianos adscritos a la tribu Sergia, y más tarde, veteranos de Augusto para la tribu Galeria. ${ }^{65}$

No obstante, existen determinados indicios en la documentación epigráfica y arqueológica que permiten aproximarnos a las primeras familias de colonos sepultadas en la necrópolis salariense. Concretamente, el sillar correspondiente a CILA 7, 365 también alude, como se ha mencionado ya, a varios individuos Stlaccii; se trata de

\footnotetext{
A. Canto, comentario a HEp 14, 2005, 192.

Gimeno 2004-2005, 181-184.

Stylow 1995, 117-121.

65 González 1999.
} 
un gentilicio con escasa implantación en suelo hispano, ${ }^{66}$ pues, además del epígrafe de Salaria, solo se constata en dos individuos registrados en un epitafio sepulcral del siglo I d.C. en Gades,${ }^{67}$ y en el de una dama del siglo I d.C. en Hispalis. ${ }^{68}$ En la Península Itálica son una de las familias más antiguas de Puteoli, conformando parte de la aristocracia local en los primeros tiempos de la colonia, según ha analizado Filippo Demma. ${ }^{69}$ Asociado a este sillar se vinculan diversas piezas pétreas decoradas, cornisas, relieves, una figura de león que apoya su zarpa izquierda sobre una cabeza humana y una estatua velada, depositadas en el Museo Arqueológico de Úbeda; han sido analizadas profusamente por Beltrán y Baena, ${ }^{70}$ con una hipótesis de reconstrucción del monumento funerario de tipo turriforme coronado con edícula, que vinculan a un mausoleo de uso familiar.

En relación a este conjunto podemos comentar que, a partir de los caracteres paleográficos y del estudio arquitectónico del monumento funerario, el momento concreto podría datarse en época tardoaugustea o tiberiana. Este planteamiento es, a mi juicio, complementario con las posturas anteriores. Se trataría de una gens que pudo pertenecer a la primera o segunda generación de las familias descendientes de los colonos fundadores, y que mantienen su tribu. La presencia de estos Stlaccii en el panorama onomástico revela la migración de itálicos a las tierras del Alto Guadalquivir, población que se instaló en este centro de nueva creación y bien ubicado con respecto a las rutas comerciales entre el Guadalquivir y el levante hispano. Formaron parte de la élite social de Salaria, aunque desconocemos el papel específico que ejercieron en la colonia; podemos apuntar varias líneas: por una parte, que se tratase de antiguos legionarios, en cuyo caso, tendría que quedar explicitada su legión o antiguo cargo militar, que no es el caso; también podemos considerar que fuesen comerciantes vinculados con la exportación de sal, dada la abundancia de salinas en el territorio circundante ${ }^{71} \mathrm{o}$ incluso indicar que fuesen gentes de negocios que habían fijado su residencia con objeto de ocuparse de sus intereses en esta zona; concretamente, pudieron ser uno de los grupos itálicos que gestionaban in situ las cercanas minas de Castulo, ser dueños de alguna de las concesiones mineras o formar parte de la societas Castulonensis.

Contamos con otro testimonio epigráfico alusivo a las especiales vinculaciones que la colonia de Salaria mantiene con la casa imperial y que constata los momentos posteriores a la deductio colonial en época tardoaugustea; se trata del ya aludido epígrafe correspondiente a $\operatorname{CILA} 7,357,{ }^{72}$ un bloque de piedra dedicado a uno de los hijos adoptivos de Augusto, Cayo o Lucio César, como patrono de la colonia justo en el momento en el que fueron proclamados herederos de Augusto y con anterioridad a su temprana defunción; este epígrafe permite pensar que pueda adscribirse a un recinto consagrado al culto imperial o templo dinástico, cronológicamente datable entre el 6 a.C. y antes del 4 ó 2 a.C.

\footnotetext{
Abascal 1994, 223.

67 CIL II 6285c (=IRPCa 330): [T(itus) St]lac[cius] / Sodalis ann(orum) / XVIII h(ic) s(itus) e(st) s(it) t(ibi) t(erra) l(evis) / T(itus) Stlaccius / Secundus / anno(rum) XXIV s(it) t(erra) l(evis). 
Este acontecimiento también se celebró en otras ciudades del Alto Guadalquivir: así en Castulo, de donde procede un fragmento de un pedestal (CILA 6, 82; Fig. 6), datado en el 3 d.C., que testimonia la dedicación de monumentos a Caius Caesar, el mayor de los hermanos, o en Urgavo, donde otros dos textos transmitidos por la tradición anticuaria (CILA 7, 562 y 563) señalan la erección de pedestales dedicados a Lucio César en el 2 a.C. Se trata de evidencias epigráficas que debemos poner en relación con las honras fúnebres decretadas por Augusto a estos principes iuventutis, tras el fallecimiento de ambos en el 4 y 2 a.C.

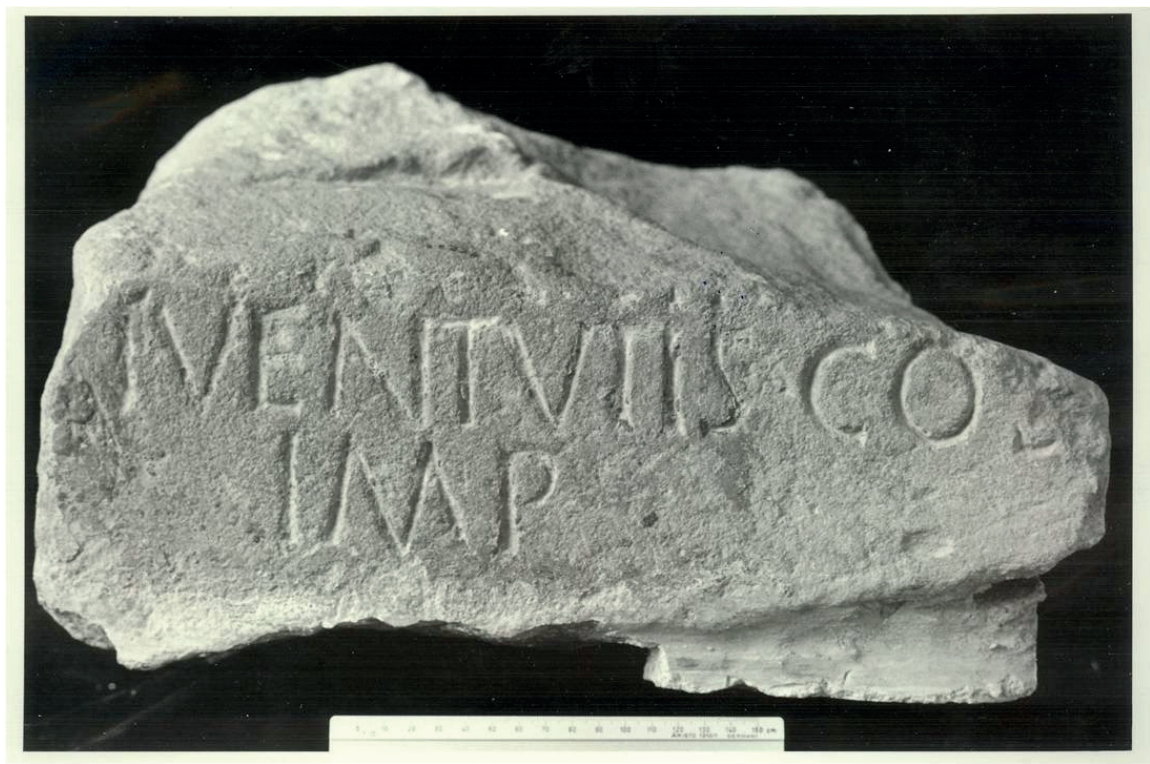

Figura 6. CILA 6, 82: Parte inferior de la inscripción honorífica dedicada a Cayo César, princeps iuventutis, de Castulo.

La colonia de Tucci (Martos), proyectada por Augusto entre el 25 y 14 a.C., se asienta junto a los ríos Eliche y Víboras, y se fundó con veteranos de origen itálico procedentes de las legiones IIII Macedonica ${ }^{73}$ y X Gemina ${ }^{74}$ vinculadas a la lucha contra los cántabros y astures. Las informaciones más completas de Tucci se encuentran en Plinio ${ }^{75}$ quien la incluye entre las comunidades de ciudadanos romanos del Conventus Astigitanus, dotada de la immunitas y del dominium, es decir, en la propiedad plena de la tierra. Los nuevos ciudadanos fueron adscritos a la tribu Sergia,${ }^{76}$ aunque también aparecen la Voltinia, ${ }^{77}$ la Galeria $^{78}$ y la Quirina $;{ }^{79}$ la pre-

\footnotetext{
CIL II $1681\left(=C I L A 7,442=C I L I^{2} / 5,82\right)$ y $C I L$ XIII 6856.

74 CIL II 1691 (=CILA 7, 451=CIL II $\left.{ }^{2} / 5,83\right)$ y $A E 1929,189$.

75 Plin. HN 3.3.12.

76 CIL II $1710\left(=C I L\right.$ II $\left.^{2} / 5,130=C I L A ~ 7,482\right), C I L$ II $1682\left(=C I L I^{2} / 5,118=C I L A 7,443\right)$ y $C I L$ II $1690(=C I L$ $\mathrm{II}^{2} / 5,81=C I L A$ 7, 450): Ser(gia). CIL II $1684\left(=C I L \mathrm{II}^{2} / 5,91=C I L A\right.$ 7, 445): [S]er(gia). CIL II $1666\left(=C I L \mathrm{II}^{2} / 5\right.$, 72=CILA 7, 425), CIL II 5473 (=CIL II ${ }^{2} / 5,107=C I L A ~ 7,436, C I L$ II 1680 (=CIL II ${ }^{2} / 5,88=C I L A$ 7, 441), CIL II 1681 (=CIL II $2 / 5,82=C I L A$ 7, 442) y CIL II 1687 (=CIL II $\left.{ }^{2} / 5,99=C I L A ~ 7,447\right): \operatorname{Serg}(\mathrm{ia})$.

77 CIL II $1713\left(=\right.$ CIL II $\left.{ }^{2} / 5,106=C I L A 7,487\right)$.

78 CIL II $\left.1700\left(=C I L \mathrm{II}^{2} / 5,110=C I L A\right) 7,460\right)$.

79 CIL II $1685\left(=C I L I^{2} / 5,93=C I L A ~ 7,446\right)$.
} 
sencia de Iulii en el panorama onomástico refuerza su fundación augustea. Concretamente, miembros como Q. Iulius Celsus, del reinado de Augusto ${ }^{80}$ desconocemos la circunstancias concretas que justificaron la erección del posible pedestal por él dedicado, debido a que el texto transmitido por la tradición anticuaria se encuentra fragmentado (Fig. 7); no obstante, debemos subrayar que su gentilicio posiblemente traduzca una relación social específica, dadas las peculiaridades del censo colonial de la deductio. En cualquier caso, no se trató de la única dedicación dirigida al fundador del principado y de la colonia, ya que la tradición anticuaria nos ha transmitido otro pedestal honorífico $\left(C I L \mathrm{II}^{2} / 5,198\right)$, dedicado también a Augusto por C. Iulius Scaena, decurio equitum y centurio hastatus primus, que alcanzó el duovirato durante época augustea o tiberiana, etc. ${ }^{81}$ No se han conservado los edificios de la colonia, aunque según noticias del s. XVIII bajo las actuales plazas de la Constitución y Santa Marta se ubicaría el forum coloniae. También en la Colección arqueológica del Colegio San Antonio en Martos y en el Museo Provincial de Jaén se custodian diversos restos de capiteles y materiales ornamentales, procedentes de esta área, pero sin un contexto arqueológico claro. Al forum podemos adscribir los pedestales del edil y duoviro Q. Iulius Q.f. Celsus Sergia (CILA 7, 425), Anicia Postuma (CILA 7, 434), Q. Antonius (CILA 7, 435), M. Atilius Severus y Iulia Dionisia (CILA 7, 436), Cornelius Savo (CILA 7, 438), etc. Asimismo, hay que suponer la existencia de un templum dedicado a Hercules Invicto en función de la inscripción CILA 7, 417, y de otro templo dedicado al culto imperial, según se desprende de dos aras dedicadas a la Piedad Augusta (CILA 7, 420 y 421), una basa a Alfidia (CILA 7, 426) y un pedestal a Iulia Augusta (CILA 7, 427); este último documento tiene un carácter excepcional tanto por la persona a la que se honra como por el apelativo Augusta que se le adscribe.

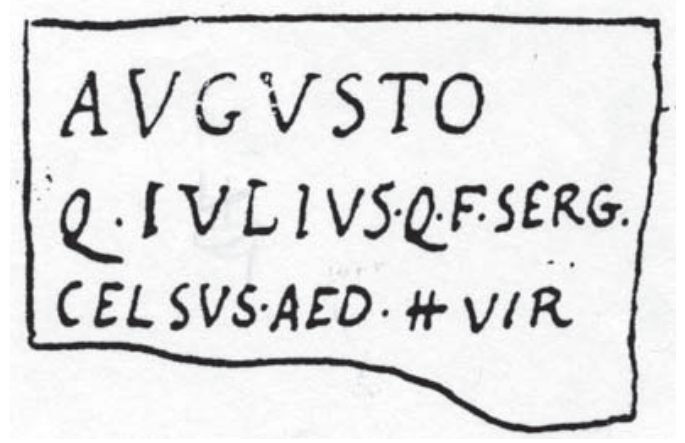

Figura 7. CIL II $2 / 5,72$ : Inscripción de Tucci con mención de la tribu Sergia (www3.uah.es/imagines_cilii/CILII/astigitanus1).

En cuanto al programa de promoción municipal de determinados núcleos urbanos, decir que Urgavo Alba -situada sobre un alto promontorio, domina la campiña de Arjona, que surcan los arroyos de Vallondo, Los Algarbes y Salado de Arjona-

\footnotetext{
80 CIL II 1664 (=CIL II $\left.{ }^{2} / 5,198=C I L A ~ 7,423\right): A u g($ usto $) ; C I L$ II 1666 (=CIL II $\left.2 / 5,72=C I L A ~ 7,425\right):$ Augusto / Q. Iulius Q.f. Serg. / Celsus aed. IIvir.

81 González Román 2011, 141, 146, n. 91.
} 
ratifica la alusión de Plinio ${ }^{82}$ como uno de los oppida celeberrima que se asientan entre el Betis y la costa del Océano. El municipio fue dotándose progresivamente con una serie de monumentales edificios en los que destaca su foro, probablemente situado en los alrededores de calles Santa María y Alcázar, aunque falta por localizar arqueológicamente. ${ }^{83}$ En función del material epigráfico, probablemente fue erigido en época de Augusto; dos dedicaciones son especialmente reseñables ${ }^{84}$ en la primera de ellas $\left(C I L \mathrm{II}^{2} / 7,70\right)$ el ordo local atribuye al príncipe el título de pater patriae en el año 6 a.C., es decir, cuatro años antes de recibirlo del Senado a petición del pueblo de Roma; en la segunda $\left(C I L \mathrm{II}^{2} / 7,69\right)$ se registra a L. Aemilius L. f. Nigellus, que ejerció el edilato y el duovirato en el 11-12 d.C. Interesante es también el texto epigráfico al que aludíamos anteriormente y que descubre a M. Horatius M.f. Gal. Bodonilur, IIvir, y a su cónyuge Lucretia L.f. Sergieton, ${ }^{85}$ (Fig. 8) ejemplo de integración de indígenas en la nueva estructura de poder local implantada en este momento.

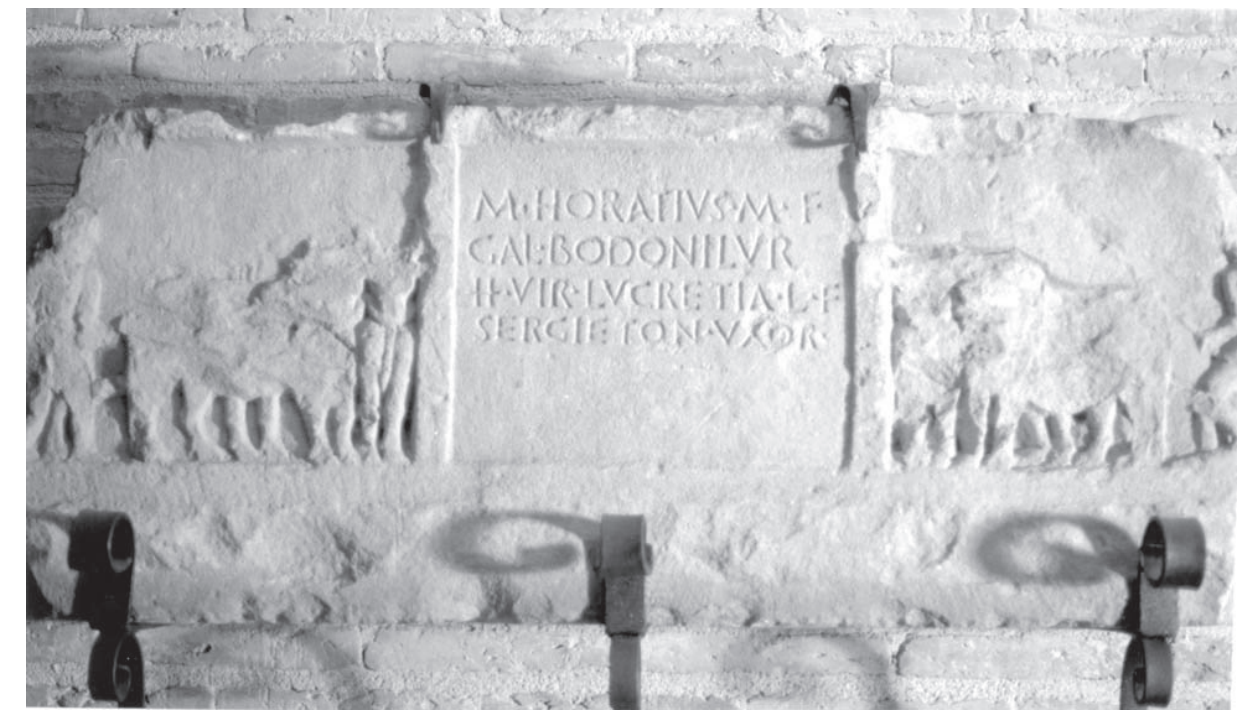

Figura 8. CIL II $2 / 7,91$ : Inscripción con onomástica latinizada de Urgavo Alba (www3.uah.es/imagines_cilii/CILII/cordubensis1.htm\#).

Asimismo, se adscriben al municipium dos textos transmitidos por la tradición anticuaria $\left(C I L I^{2} / 7,71\right.$ y 72$)$ que señalan la erección de posibles pedestales dedicados a Lucio César, hijo de Agripa y de Julia la Mayor, augur y cónsul designado, por decreto de los decuriones urgavonenses el mismo año de su defunción, el 2 a.C. Como instituciones del municipio, el pontificado también debe aceptarse ante la evi-

\footnotetext{
Plin. $H N$ 3.3.10.

83 Morales Talero 1965, 37-38.

84 CIL II 2107 (=CIL II²/7, 70=CILA 7, 560): Imp(eratori) Caesari Augusto Divi f(ilio) / pontufici max(imo) trib(unicia) potest(ate) XIIX / co(n)s(uli) XI patri patriae d(ecreto) d(ecurionum) (año 6 a.C.). CIL II 2106 $\left(=C I L I^{2} / 7,69=C I L A\right.$ 7, 559): Imp(eratori) Caesari Aug(usto) pont(ifici) max(imo) / trib(unicia) pot(estate) XXXIIII co(n)s(uli) XIII / patri patriae Victoriae sacr(um) / L(ucius) Aemilius L(uci) f(ilius) Nigellus aed(ilis) IIvir d(e) s(ua) p (ecunia) f(ecit) (año 11-12 d.C.). Las hemos puesto completas, tomados sus textos de la página de CIL 2 .

85 CIL II $2114\left(=C I L ~ I I^{2} / 7,91=C I L A 7,567\right)$.
} 
dencia epigráfica, que atestigua dos de los tres pontífices del colegio sacerdotal: $L$. Calpurnius L.f. Gal. Silvinus (CIL II $\left.{ }^{2} / 7,68\right)$, que además ejerció de flamen sacrorum publicanorum y consagró a Liber Pater Augustus una estatua durante el desempeño de su pontificado entre el 11-12 d.C., y M. Helvius M.f. Gal. Novatus (CIL II $\left.{ }^{2} 7,76\right)$, que desarrolló su actividad durante el reinado de Tiberio. Este conjunto de dedicatorias demuestran la importancia del municipio en época augustea, unido a la probable existencia de templos dedicados a César Augusto y familia.

Finalmente, señalar que a partir de la plástica romana se tiene constancia de la existencia de un retrato adscrito a Augusto, procedente del barrio de la Magdalena de Jaén, aunque sin un contexto arqueológico claro; catalogado del tipo Actium o Alcúdia, ${ }^{86}$ está datado a comienzos de los años veinte del siglo I a.C. y es considerado una de las imágenes imperiales más antiguas realizadas en Hispania. Resulta curiosa esta datación ya que, en estos momentos, el enclave podría ser un oppidum stipendiarium, manteniendo tal condición jurídica hasta época flavia, en la que se transforma en municipium flavium Aurgitanum, tal y como aparece reflejado en diversos epígrafes procedentes de finales del siglo I y principios del siglo II d.C. Tal promoción se constata en el nombre del municipio (atestiguado en cinco ocasiones) y en la adscripción de sus habitantes a la tribu Quirina ${ }^{87}$ Su relación con Roma en este momento queda por averiguar; podríamos apostar por un elemento de conexión con la fase pre-municipal, donde se va produciendo una adaptación gradual a las formas organizativas romanas con anterioridad a la concesión del estatuto municipal; o bien, pensar en una imagen que se emplaza en el foro de la ciudad en el momento de su promoción o en última instancia se reutiliza.

\section{Conclusiones}

La implantación romana en el Alto Guadalquivir evidencia un alto grado de romanización, remarcada por la tradición literaria clásica y que tiene la respectiva proyección epigráfica y arqueológica. Se destaca la extensión del ordenamiento municipal, especialmente en el caso de los municipios cesarianos de Iliturgi, Isturgi, Obulco, Ossigi y Urgavo, expresada fundamentalmente en una afinidad política de carácter clientelar con el vencedor de la guerra civil. En las ciudades romanas analizadas este proceso es resultado de una creación ex nihilo por parte de Roma, como puntualmente se evidencia en Tucci y en Salaria. La colonia de Tucci se funda mediante la aportación de contingentes de población procedentes de las legiones IIII Macedonica y X Gemina, y Salaria con veteranos no documentados epigráficamente. En las fundaciones de las colonias se proyectan elementos de índole económica, vinculados con las posibilidades agrarias que brinda el respectivo ager, que se verá modificado por la proyección de la centuriatio y por el prototipo de explotación agraria, definido como villa, y de carácter estratégico asociado al dominio de las poblaciones y a la articulación territorial del imperio.

Por otro lado, a través del análisis detallado de la documentación podemos deducir ciertos datos de interés. En primer lugar, la importancia de la vida urbana como base fundamental en la articulación del territorio en época romana. Los distintos núcleos se organizan en torno a diversas redes de comunicación fundamentales, unas

González Navarrete 1967, 31; Baena 1999, 210-211; Baena - Beltrán 2002, 76; Garriguet 2008, 119.

Morales Rodríguez 2002, 32. 
que parten desde Castulo hacia el Levante, a través de la vía Castulo-Libisosa; otras alineadas por el valle del Guadalquivir en la ruta Castulo-Corduba o, finalmente, otro grupo establecido hacia el sur, en la calzada Castulo-Malaca. Por otra parte, los recursos mineros y agrícolas que se localizan en los agri de estas comunidades son esenciales. La explotación de las minas de Sierra Morena, la sal de la comarca de La Loma, las producciones de olivo y cereal de la Campiña y la riqueza forestal del saltus tugiensis, zona maderera importante para la actividad constructiva, etc., son medios disponibles para el desarrollo de este conjunto de ciudades.

Asimismo, los ejes principales de este ordenamiento territorial están constituidos por las colonias de Salaria y Tucci. Las ciudades ex novo implantan una nueva estructuración y condicionan el territorio de las ciudades preexistentes. Consecuencia de la implantación romana será la llegada de elementos exógenos a la zona, con la colonización de contingentes de origen latino, adscritos a la tribu Sergia; destacar la presencia de Stlacii en Salaria o Iulii en Tucci. Aunque escasa, se constata la aculturación del elemento indígena, a través de la latinización del sistema onomástico y hay que anotar la destacable presencia de ciudadanos adscritos a la Galeria tribus.

Para concluir, es necesario indicar que el conocimiento de la superficie urbana de estos enclaves tropieza con distintos obstáculos derivados de la continuidad ocupacional, lo que impide la demarcación de la ciudad romana. No obstante, la incorporación en el sistema de beneficios intrínsecos a la ciudad romana se materializa urbanísticamente por la proyección de programas monumentales, en los que se revela la fidelidad al imperio; entre ellos, se encuentra el templo dinástico, cuya existencia puede reconstruirse en diversos homenajes rendidos al Princeps; la mayoría de las inscripciones están dedicadas simplemente a Augusto o a César Augusto, sin referencia alguna a sus titulaturas, como es habitual en los epígrafes dedicados a los emperadores, ejemplos de Tucci. Hay que destacar las manifestaciones de culto dinástico reflejadas en los epígrafes de Castulo, Salaria y Urgavo dedicados a los hijos adoptivos del emperador, Gayo y Lucio César, prueba de la atención con la que la zona seguía los acontecimientos ocurridos en el seno de la domus Augusta.

\section{Referencias bibliográficas}

Abascal Palazón, J. M.

(1994): Los nombres personales en las inscripciones latinas de Hispania, Murcia.

(1996): "Programas epigráficos augusteos en Hispania", Anales de Arqueología Cordobesa 7, 45-82.

Alföldy, G. (1973): Flamines Provinciae Hispaniae Citerioris (=Anejos de AEspA VI), Madrid.

Álvarez García, J. (2014): "La consagración a Augusto en la epigrafía hispánica", Ab Initio 9, 3-60.

Arteaga, O. (1985): "Excavaciones arqueológicas sistemáticas en el Cerro de los A1cores (Porcuna, Jaén). Informe preliminar sobre la campaña de 1985", Anuario Arqueológico de Andalucía 1985. II Actividades sistemáticas, 279-287.

Arteaga, O. - Blech, M. (1986): "La romanización en las zonas de Porcuna y Mengíbar”, [en] Los asentamientos ibéricos ante la romanización, Madrid, 89-99. 
Arteaga, O. - Ramos, J. - Ros, A. M. (1990): "El abandono de un sector urbano de Obulco en época flavia", Anuario Arqueológico de Andalucía 1990. II Actividades sistemáticas, 310-317.

Baena del Alcázar, L. (1999): "El retrato romano de Augusto del Museo de Jaén”, Baetica 21, 207-216 (http://dx.doi.org/10.24310/BAETICA.1999.v0i21.490).

Baena del Alcázar, L. - Beltrán Fortés, J. (2002): Esculturas romanas de la provincia de Jaén (=CSIR 1.2), Murcia.

Bellón Ruiz, J. P. et alii (2015): "El Proyecto Baecula: historia de una investigación”, [en] Bellón Ruiz et alii (eds.), 2015, 195-232.

Bellón Ruiz, J. P. - Ruiz Rodríguez, A. - Molinos Molinos, M. - Rueda Galán, C. - Gómez Cabeza, F. (eds.), (2015): La Segunda Guerra Púnica en la península ibérica. Baecula: arqueología de una batalla (=Serie Textos CAAI 7), Jaén.

Beltrán Fortes, J. - Loza Azuaga, M. L. (2005): "El “oso de Porcuna”. Una escultura funeraria excepcional de la Hispania romana", Romula 4, 163-176.

Bendala Galán, M.

(1990): "El plan urbanístico de Augusto en Hispania: precedentes y pautas macroterritoriales", [en] Stadtbild und Ideologie. Die Monumenatalisierung hispanischer Städte zwischen Republik und Kaiserzeit, München, 25-42.

(1998): "Fórmulas de promoción y desarrollo urbano y urbanístico en la Hispania tardorrepublicana", [en] J. Mangas Manjarrés (ed.), Italia e Hispania en la crisis de la República Romana. Actas del III Congreso Hispano-Italiano (Toledo, 1993), Madrid, 307-312.

Canto de Gregorio, A.

(1999): “Ilorci, Scipionis rogus (Plinio, NH III, 9) y algunos problemas de la Segunda Guerra Púnica en Hispania”, Rivista Storica dell'Antichitá 29/1, 127-167. (2015): "La importancia estratégica del Alto Guadalquivir durante la Segunda Guerra Púnica, y el sitio de Ilorci-Amturgi”, [en] Bellón Ruiz et alii (eds.), 2015, 163-192.

Castillo, C. (1988): "La tribu Galeria en Hispania. Ciudades y ciudadanos", [en] J. González - J. Arce (ed.), Estudios sobre la Tabula Siarensis (=Anejos de AEspA IX), Madrid, 233-243.

Ceán Bermúdez, J. A. (1832): Sumario de las antigüedades romanas que hay en España, Madrid.

Cortijo Cerezo, M. L. (1993): La administración territorial de la Bética romana (=Colección Plaza Mayor 12), Córdoba.

Chica Casinello, G. La (1956-1961): “Inscripción dedicada a Tiberio Sempronio Graco", Noticiario Arqueológico Hispánico V, 178-180.

Curchin, L. A. (1990): The Local Magistrates of Roman Spain (=Phoenix Suppl. 28), Toronto.

Demma, F. (2007): Monumenti pubblici di Puteoli: per un archeologia dell'architettura, Roma.

Díaz Ariño, B. (2008): Epigrafía latina republicana de Hispania (=Universitat de Barcelona. Col·lecció Instrumenta 26), Barcelona (=ELRH).

D’Ors y Pérez-Peix, A. (1953): Epigrafía Jurídica de la España Romana, Madrid.

Fasolini, D. (2012): Le tribù romane della Hispania Tarraconensis. L'ascrizione tribale dei cittadini romani nelle testimonianze epigrafiche, Milano.

Fernández, M. I. - Ruiz, P. - Peinado, M. V. (2008): “El proyecto Isturgi: reformularse o morir”, Boletín del Instituto de Estudios Giennenses 198, 173-188. 
Fornell Muñoz, A. (2015): "El Alto Guadalquivir en época Augustea”, [en] Márquez Moreno - Melchor Gil (coords.), 2015, 13-37.

Gabba, E. (1973): "Sull'emigrazione romano-italica in Spagna nel II sec. a.C.", [en] E. Gabba, Esercito et società nella tarda Repubblica romana (=Il Pensiero Storico 62), Firenze, 289-299.

Garriguet Mata, J. A. (2008): "Retratos imperiales de Hispania", [en] J. M. Noguera Celdrán - E. Conde Guerra (eds.), Escultura romana en Hispania V, Murcia, 115-147.

Gimeno Pascual, H. (2004-2005): "Nuevos datos para la colonia Salaria", Lucentum XXIII-XXIV, 181-184 (http://dx.doi.org/10.14198/LVCENTVM).

González Fernández, J.

(1982): Inscripciones romanas de la provincia de Cádiz, Cádiz (=IRPCa).

(1989): “Urso, ¿tribu Sergia o Galeria?”, [en] J. González Fernández (ed.), Estudios sobre Urso, Colonia Iulia Genetiva (=Alfar. Serie Investigación y Ensayo 45), Sevilla, 133-153.

(1991): Corpus de inscripciones latinas de Andalucía. Volumen II. Sevilla. Tomo I: La Vega (Hispalis), Sevilla (=CILA 2).

(1999): Ciudades privilegiadas en el Occidente romano (=Universidad de Sevi1la. Serie Historia y Geografía 42), Sevilla.

González Navarrete, J. A. (1967): “Museo de Jaén”, Boletín del Instituto de Estudios Giennenses 52, 31.

González Román, C. (2011): “Colonia Augusta Gemella Tucci (Martos, Jaén)”, [en] J. González Fernández - J. C. Saquete Chamizo (eds.), Colonias de César y Augusto en la Andalucia romana (=L'Erma di Bretschneider. Hispania Antigua. Serie Histórica 6), Roma, 129-165.

González Román, C. - Mangas Manjarrés, J. (1991): Corpus de inscripciones latinas de Andalucía. Volumen III, Jaén, Sevilla (=CILA 6-7).

Knapp, R. C. (1980): "La epigrafía y la historia de la Córdoba romana", Anuario de Filología 6, 61-71.

Kubitschek, W. (1972): Imperium Romanum Tributim Discriptum, Roma.

Lostal Pros, J. (1992): Los miliarios de la provincia Tarraconense (conventus Tarraconense, Caesaraugustano, Cluniense y Cartaginense), Zaragoza.

Mangas Manjarrés, J. (1986): "Die römische Religion in Hispanien wahrend der Prinzipatszeit", Aufstieg und Niedergang der römischen Welt II.18.1, 337-340.

Mangas Manjarrés, J. - Hernando Sobrino, $\mathrm{M}^{\mathrm{a}} \mathrm{R}$.

(1990-1991): "La sal y las relaciones intercomunitarias en la Península Ibérica durante la Antigüedad", Memorias de Historia Antigua 11-12, 219-332. (2011): La sal en la Hispania romana, Madrid.

Marín Díaz, M. A. (1988): Emigración, colonización y municipalización en la Hispania republicana, Granada.

Márquez Moreno, C. - Melchor Gil, E. (coords.), (2015): La Bética en tiempos de Augusto. Aspectos históricos y arqueológicos, Córdoba.

Melchor Gil, E. - Rodríguez Neila, J. F. (2003): "Magistrados municipales y munificencia cívica en las provincias de Bética y Lusitania", [en] S. Armani - A. U. Stylow (coords.), Epigrafia y sociedad en Hispania durante el Alto Imperio: estructuras y relaciones sociales. Actas de la mesa redonda organizada por la Casa de Velázquez, el Centro CIL II de la Universidad de Alcalá y L'Année épigraphique (=Acta Antiqua Complutensia 4), Alcalá de Henares, 209-239. 
Molina Fajardo, F. et alii (1978): "La Edad del Bronce en el Alto Guadalquivir: excavaciones en Úbeda", Boletín del Instituto de Estudios Giennenses 95, 37-58.

Morales Rodríguez, E. M.

(2002): Los municipios flavios en la provincia de Jaén, Jaén.

(2013): "Las ciudades romanas en el Alto Guadalquivir", Trastámara 11/2, 77 98.

(2014): "Epigrafía legionaria en el Alto Guadalquivir", [en] G. Bravo Castañeda - R. González Salinero (eds.), Conquistadores y conquistados. Relaciones de dominio en el mundo romano (=Signifer. Monografías y Estudios de la Antigüedad Griega y Romana 43), Madrid-Salamanca, 217-232.

(2015): "Augusto y familia: su presencia en las ciudades romanas del Alto Guadalquivir”, [en] Márquez Moreno -Melchor Gil (coords.), 2015, 89-101.

Morales Talero, S. (1965): Anales de la ciudad de Arjona, Arjona.

Ozcáriz Gil, P. (2013): La administración de la provincia Hispania Citerior durante el Alto Imperio (=Universitat de Barcelona. Col·lecció Instrumenta 44), Barcelona.

Pastor Muñoz, M. (2013): "Viriato en el ámbito tuccitano”, Trastámara 11/2, 5-31.

Pons, J. (1977): "Algunas consideraciones sobre el sevirado como indicador de dinamismo socio- económico", Memorias de Historia Antigua 1, 215-219.

Portillo, R. (1982): “Algunas notas en torno al desempeño del sevirato por los íncolas", [en] J. Higueras Maldonado (coord.), I Congreso Andaluz de Estudios Clásicos, Jaén, 364-367.

Recio Veganzones, A. (1969): "Nueva epigrafía tuccitana”, Boletín del Instituto de Estudios Giennenses 59, 11-55.

Richardson, J. S. (1998): "Una tierra de promisión", [en] J. Arce et alii (eds.), Hispania Romana. Desde tierra de conquista a provincia del imperio, Madrid, 67-72.

Ruiz Rodríguez, A. - Molinos Molinos, M. (2015): Jaén, tierra íbera. 40 años de investigación y transferencia, Jaén.

Sayas Abengoechea, J. J.

(1978): "Organización interna de las ciudades hispanas", Historia de España Antigua. II, Madrid, 377.

(1989): "Colonización y municipalización bajo César y Augusto: Bética y Lusitania", [en] Aspectos de la colonización y municipalización de Hispania (=Cuadernos Emeritenses 1), Mérida, 33-70.

Silliéres, P. (1976): "Un grupo de cuatro miliarios en La Cerradura", Boletín del Instituto de Estudios Giennenses 90, 55-70.

Solana Sáinz, J. M. (1989): “Colonización y municipalización bajo César y Augusto: Hispania Citerior", [en] Asociación Amigos del Museo (ed.), Aspectos de la colonización y municipalización de Hispania, Mérida, 71-106.

Stylow, A. U.

(1993): "De Corduba a Colonia Patricia. La fundación de la Corduba romana", [en] Ma P. León Alonso (coord.), Colonia Patricia Corduba. Una reflexión arqueológica, Córdoba, 77-85.

(1995): “Apuntes sobre las tribus romanas en Hispania", Veleia 12, 105-123.

Wiegels, R. (1982): "Iliturgi und der deductor Ti. Sempronius Gracchus", Madrider Mitteilungen 23, 152-221. 